\title{
Tick-borne pathogen detection in midgut and salivary glands of adult Ixodes ricinus
}

\author{
Emilie Lejal' ${ }^{1}$ Sara Moutailler ${ }^{1}$, Ladislav Šimo ${ }^{1}$, Muriel Vayssier-Taussat ${ }^{2}$ and Thomas Pollet ${ }^{* *}$
}

\begin{abstract}
Background: The tick midgut and salivary glands represent the primary organs for pathogen acquisition and transmission, respectively. Specifically, the midgut is the first organ to have contact with pathogens during the blood meal uptake, while salivary glands along with their secretions play a crucial role in pathogen transmission to the host. Currently there is little data about pathogen composition and prevalence in Ixodes ricinus midgut and salivary glands. The present study investigated the presence of 32 pathogen species in the midgut and salivary glands of unfed I. ricinus males and females using high-throughput microfluidic real-time PCR. Such an approach is important for enriching the knowledge about pathogen distribution in distinct tick organs which should lead to a better understanding I. ricinusborne disease epidemiology.

Results: Borrelia lusitaniae, Borrelia spielmanii and Borrelia garinii, were detected in both midgut and salivary glands suggesting that the migration of these pathogens between these two organs might not be triggered by the blood meal. In contrast, Borrelia afzelii was detected only in the tick midgut. Anaplasma phagocytophilum and Rickettsia helvetica were the most frequently detected in ticks and were found in both males and females in the midgut and salivary glands. In contrast, Rickettsia felis was only detected in salivary glands. Finally, Borrelia miyamotoi and Babesia venatorum were detected only in males in both midguts and salivary glands. Among all collected ticks, between $10-21 \%$ of organs were co-infected. The most common bacterial co-infections in male and female midgut and salivary glands were Rickettsia helvetica + Anaplasma phagocytophilum and Rickettsia helvetica + Borrelia lusitaniae, respectively.

Conclusions: Analysing tick-borne pathogen (TBP) presence in specific tick organs enabled us to (i) highlight contrasting results with well-established transmission mechanism postulates; (ii) venture new hypotheses concerning pathogen location and migration from midgut to salivary glands; and (iii) suggest other potential associations between pathogens not previously detected at the scale of the whole tick. This work highlights the importance of considering all tick scales (i.e. whole ticks vs organs) to study TBP ecology and represents another step towards improved understanding of TBP transmission.
\end{abstract}

Keywords: Tick-borne pathogens, Pathobiome, Salivary glands, Midgut, Ixodes ricinus, Co-infections

\section{Background}

Ticks are vectors of a large number of pathogenic microorganisms including bacteria, protozoa and viruses, which cause serious diseases in both humans and animals. Ixodes ricinus is the predominant tick species in Europe and is recognised as the primary vector of

\footnotetext{
*Correspondence: thomas.pollet@vet-alfort.fr

${ }^{1}$ UMR BIPAR, Animal Health Laboratory, INRA, ANSES, Ecole Nationale

Vétérinaire d'Alfort, Université Paris-Est, Maisons-Alfort, France

Full list of author information is available at the end of the article
}

infectious diseases in humans, including Lyme borreliosis caused by Borrelia burgdorferi (sensu lato). Over the past decade, the number of studies characterizing pathogens carried by $I$. ricinus has considerably increased, enriching the wealth of information on I. ricinus pathogen composition [1-11]. It is also important to note that I. ricinus is regularly found to be co-infected by several pathogenic agents $[6,8,12-14]$. This information is crucial considering that different co-infection combinations in humans and animals are highly likely to alter disease symptoms and severity [15-18]. The vast majority of reports

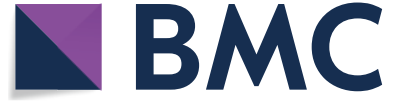

(c) The Author(s) 2019. This article is distributed under the terms of the Creative Commons Attribution 4.0 International License (http://creativecommons.org/licenses/by/4.0/), which permits unrestricted use, distribution, and reproduction in any medium, provided you give appropriate credit to the original author(s) and the source, provide a link to the Creative Commons license, and indicate if changes were made. The Creative Commons Public Domain Dedication waiver (http://creativecommons.org/ publicdomain/zero/1.0/) applies to the data made available in this article, unless otherwise stated. 
focusing on pathogen detection in I. ricinus have investigated intact bodies of adult ticks or pools of nymphs; however, such methods cannot take into account organspecific pathogen distribution. This information becomes significant as tick midgut and salivary glands act as specific and distinct barriers to efficient pathogen transmission, and are thus the main determinants influencing the acquisition, maintenance, and transmission of pathogens by ticks. Salivary glands may be co-infected by several different pathogens which can then be transmitted to the vertebrate host during blood-feeding along with salivary secretions [19-21]. Moreover, the tick midgut presents a pivotal microbial entry point and determines pathogen colonization and survival in the tick [22]. The common pathogenic life-cycle within the tick vector starts with ingestion of the infected host blood, pathogen migration through the gut to the haemocoel, transport into and infection of the salivary glands, then transmission to another host during the next blood meal. This pathway can vary depending on the pathogenic agent. For example, Borrelia and Bartonella species are known to be "stored" in the gut and migrate to the salivary glands during the next blood meal [23], thus suggesting that blood meals trigger this migration from the midgut. In contrast, Anaplasma and Ehrlichia species are able to replicate in the midgut and migrate to the salivary glands in unfed ticks [24]. The infection/transmission cycle of Babesia species is similar to that of this second group, except that tick tissues are infected by different parasitic developmental stages [25]. While multiple different pathogens are now known to co-infect whole I. ricinus ticks, it is critical to identify pathogen presence at a finer scale in tick organs, to deepen our knowledge on pathogen associations and transmission and offer new insights into TBP and tick-borne diseases. By testing for the presence of 32 TBP species in both midgut and salivary glands of I. ricinus males and females using the microfluidic realtime PCR approach, we aimed to detect pathogens in both of these key tick organs intimately involved in pathogen acquisition and transmission. Our study has consequently generated new hypotheses to understand TBP transmission.

\section{Results}

Of the collected ticks, $73 \%$ of males and $59 \%$ of females were infected by at least one pathogen (Fig. 1), and of all Anaplasma and Rickettsia species tested in the study, only Anaplasma phagocytophilum, Rickettsia helvetica and Rickettsia felis were detected (Fig. 2, Table 1). Anaplasma phagocytophilum and $R$. helvetica were detected in both salivary glands and midguts in males and females. Anaplasma phagocytophilum was detected in $23 \%$ of male organs, and $17 \%$ of female midgut and salivary glands (Fig. 2). Rickettsia helvetica infection rates reached 27 and $20 \%$ in male midgut and salivary glands, respectively, whereas in females, infection rates were $14 \%$ in both midgut and salivary glands. Both A. phagocytophilum and $R$. helvetica were mostly simultaneously detected in both organs, and were occasionally found in either only the midgut or salivary glands (Table 1). Rickettsia felis was detected only in salivary glands in males and females with an infection rate reaching $7 \%$ in

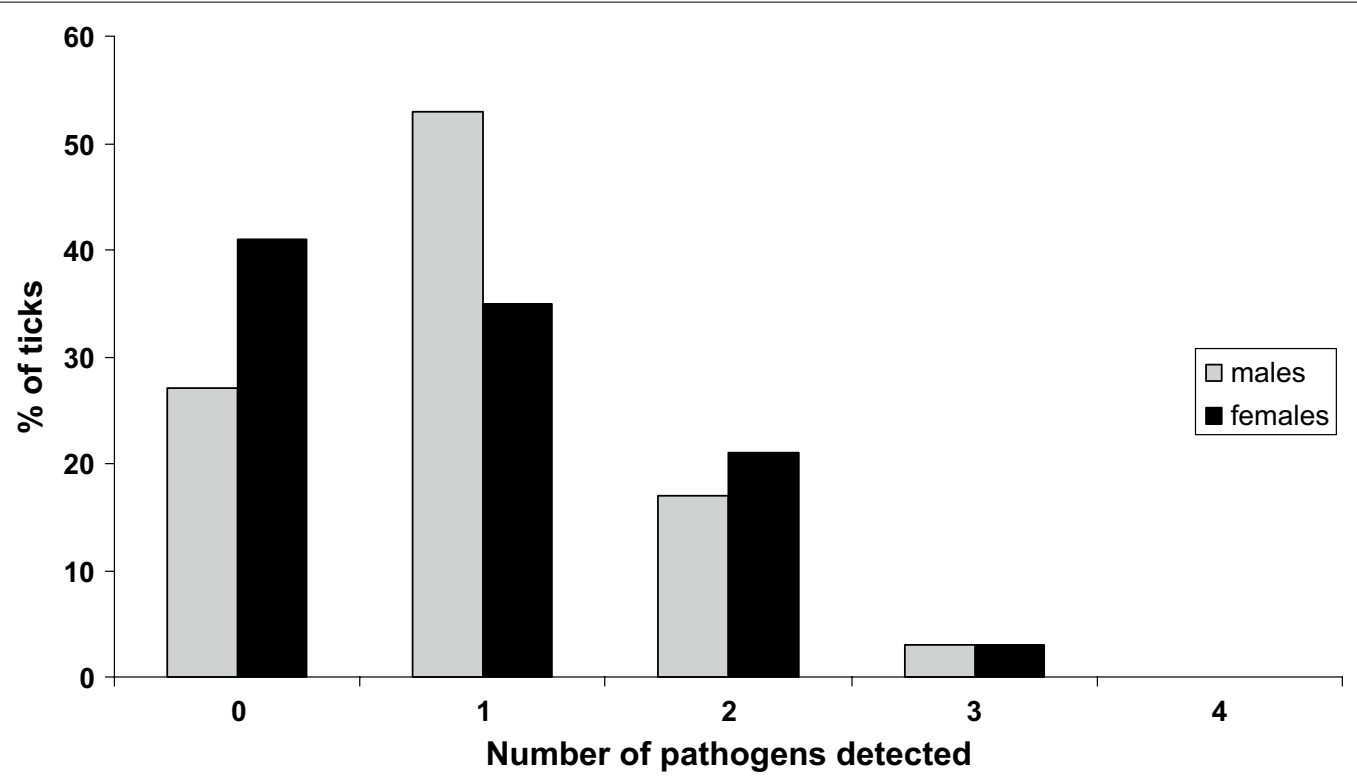

Fig. 1 Pathogen infection rates (\%) in /xodes ricinus males and females, according to the number of pathogens detected 


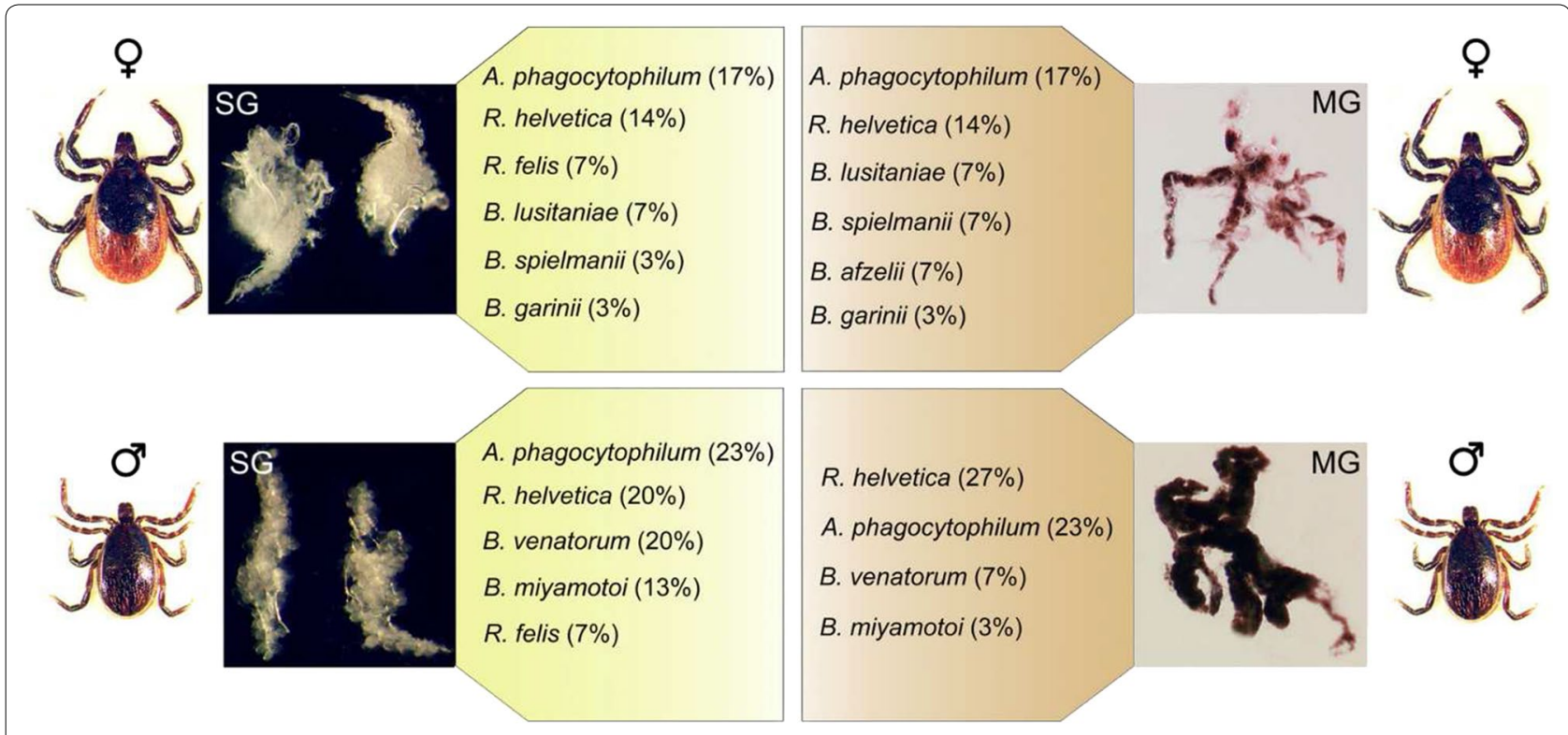

Fig. 2 Pathogen infection rates (\%) in salivary glands (SG) and midgut (MG) of unfed I. ricinus females (\$) and males (đ)

Table 1 Pathogen infection rates (\%) in females (F) and males (M) either in salivary glands alone (SG), in midgut alone (MG), or in both organs (SG/MG)

\begin{tabular}{|c|c|c|c|c|c|c|}
\hline \multirow[t]{2}{*}{ Species } & \multicolumn{3}{|c|}{ Females } & \multicolumn{3}{|c|}{ Males } \\
\hline & SG & MG & SG/MG & SG & MG & $\mathrm{SG} / \mathrm{MG}$ \\
\hline A. phagocytophilum & 7 & 7 & 10 & 3 & 3 & 20 \\
\hline R. helvetica & 3 & 3 & 10 & 7 & 13 & 13 \\
\hline R. felis & 7 & nd & nd & 7 & nd & nd \\
\hline B. lusitaniae & nd & nd & 7 & nd & nd & nd \\
\hline B. spielmanii & nd & 3 & 3 & nd & nd & nd \\
\hline B. afzelii & nd & 7 & nd & nd & nd & nd \\
\hline B. garinii & nd & nd & 3 & nd & nd & nd \\
\hline B. miyamotoi & nd & nd & nd & 10 & nd & 3 \\
\hline B. venatorum & nd & nd & nd & 13 & nd & 7 \\
\hline
\end{tabular}

Abbreviations: SG, salivary glands; MG, midgut; nd, not detected

this organ. Members of the complex Borrelia burgdorferi (s.l.) (Borrelia lusitaniae, Borrelia spielmanii, Borrelia afzelii and Borrelia garinii) were detected only in females. Borrelia lusitaniae, B. spielmanii and B. garinii were detected in both midgut $(7 \%, 7 \%$ and $3 \%$, respectively) and salivary glands (7\%, 3\% and 3\%, respectively) (Fig. 2, Table 1). Borrelia afzelii was only detected in $7 \%$ of female midguts. It is worth noting that the other members of the complex tested in this study, B. burgdorferi (sensu stricto), Borrelia valaisiana and Borrelia bissettii were not detected in either males or females. Borrelia miyamotoi was detected only in males, and mostly in salivary glands (13\%), rarely in both organs $(3 \%)$ and never in the midgut alone (Fig. 2, Table 1). The other bacterial species tested in this study, Ehrlichia canis, "Candidatus Neoehrlichia mikurensis", Bartonella henselae, Francisella tularensis, Coxiella burnetii and Mycoplasma spp. were not detected in our samples. Apicomplexa were detected in both males and females in both midguts and salivary glands. Among all tested parasites, only Babesia venatorum was only detected in males (Fig. 2, Table 1) with $7 \%$ infected in both organs, while $13 \%$ were infected only in salivary glands.

It is also important to note that $20 \%$ of males and $24 \%$ of females were co-infected. In males, $10 \%$ of midgut and $17 \%$ of salivary gland samples were co-infected (Fig. 3). In 
females, $17 \%$ of midgut and $21 \%$ of salivary gland samples were co-infected (Fig. 3). The most common co-infection in both salivary glands and midgut of males and females was $R$. helvetica $+A$. phagocytophilum and $R$. helvetica $+B$. lusitaniae, respectively.

\section{Discussion}

\section{Results contrasting with well-established postulates}

Several Borrelia burgdorferi (s.l.) genospecies (B. lusitaniae, B. spielmanii and B. garinii) were detected in ticks which was not surprising as they have already been identified in many European countries and particularly in the Senart Forest [7]. Interestingly, these species were only detected in questing females. This result supports previous findings showing that female ticks in woodland sites were more likely to be infected by B. burgdorferi (s.l.) than males and nymphs [26] suggesting potential interactions between female ticks and these bacteria. However, the most unexpected results was that we detected these species in both salivary glands and midgut which contrasts with the well-established postulate that B. burgdorferi (s.l.) genospecies are not found in salivary glands during the initial tick attachment, as they only move rapidly from the gut to the salivary glands at the beginning of the next blood meal [27-29]. Our findings would suggest that some B. burgdorferi (s.l.) genospecies do not need a blood meal to start their multiplication and migration from the gut to salivary glands. This hitherto unseen observation on field-collected ticks is completely consistent with the recent experimental results of Sertour et al. [30]. These authors detected B. burgdorferi (s.l.) strains in female salivary glands prior to blood meals, and also showed that these bacteria could infect mice within $24 \mathrm{~h}$ of a tick bite. We also note that in our study, the presence of these different $B$. burgdorferi (s.l.) genospecies in salivary glands could also be explained if not all bacteria were transmitted to the host, and that residual bacteria thus remained in salivary glands after moulting. In this case, their persistence in the salivary glands of unfed ticks would suggest that this organ could also be, as for the midgut, a potential reservoir for these spirochetes. Whichever the hypothesis, this result contributes important information to the understanding of tick-borne pathogen transmission as it suggests that several species of the B. burgdorferi (s.l.) complex could be rapidly transmitted after a tick bite.

\section{Pathogen location and migration in ticks}

Interestingly, and as has been previously observed for the other B. burgdorferi (s.l.) genospecies, B. afzelii were only detected in females, and exclusively in the midgut. These results are highly consistent with the study by

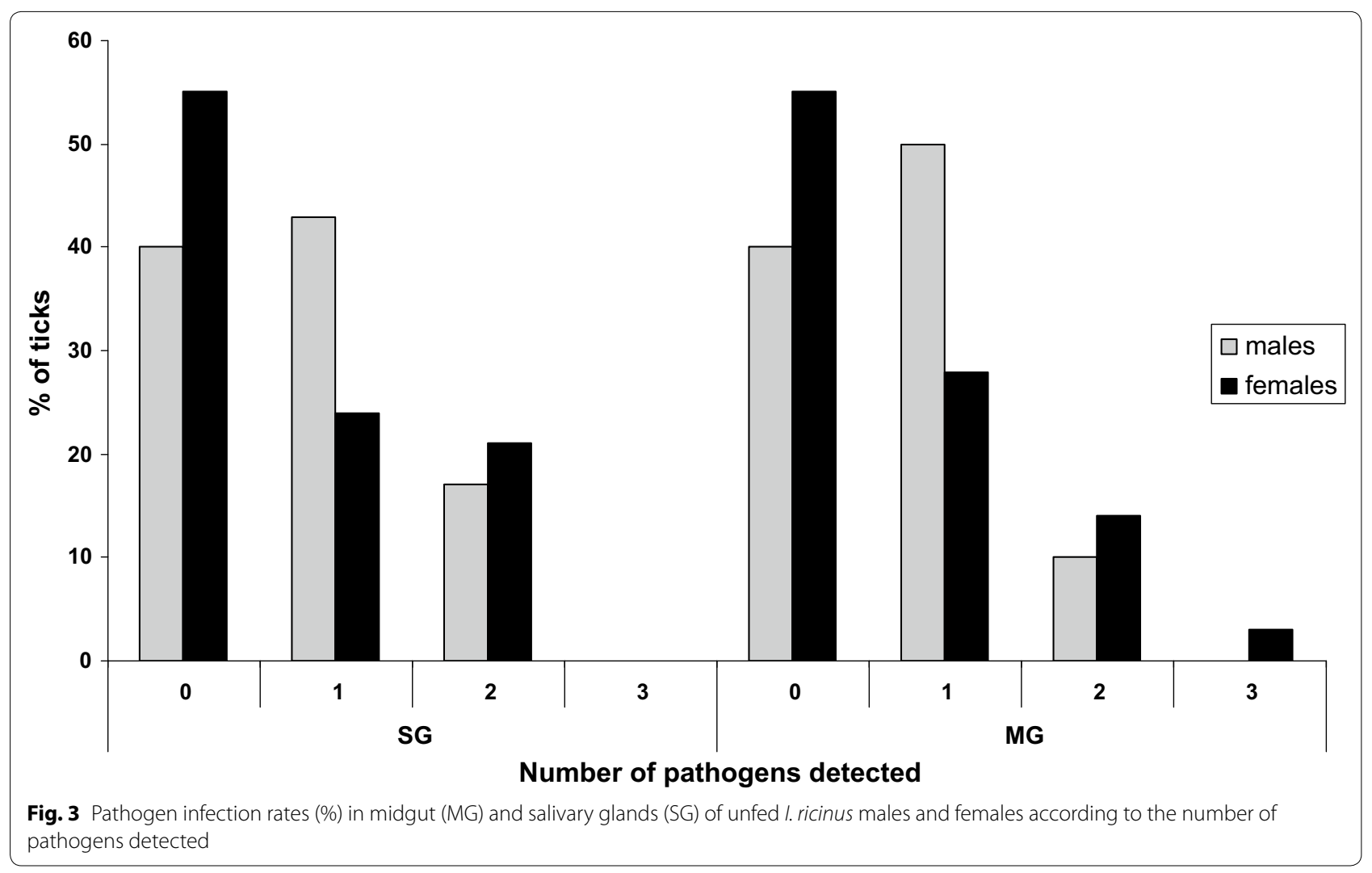


Pospisilova et al. [31] in which B. afzelii were abundant in the guts of unfed I. ricinus nymphs, whereas the spirochetes were not present in salivary glands. This result better corresponds to the previously-cited postulate and thus contrasts with the findings discussed for the other B. burgdorferi (s.l.) genospecies. This result advocates greater caution when generalising transmission mechanisms, which may differ according to B. burgdorferi (s.l.) genospecies.

We detected $R$. helvetica and A. phagocytophilum in males and females in both salivary glands and midgut, and both of these pathogenic agents were the most frequently detected in the collected ticks. Their ubiquity and high proportions in tick organs suggest that they could be well adapted to the different environmental conditions characterising both salivary glands and midgut, and thus may be stronger competitors than other pathogen species. Several studies have shown low A. phagocytophilum prevalence or titter in the salivary glands of unfed ticks [32] suggesting that pre-feeding ticks may induce bacterial replication. As "pre-feeding" is probably a rare event in the field, and that it is unlikely that all the questing ticks infected by $A$. phagocytophilum (c.20\% of infected ticks) were pre-fed, our results suggest that this bacterium could already be present in the salivary glands of unfed ticks at high infection rates. On the other hand, detecting $R$. helvetica in questing I. ricinus is not surprising as their potential presence in this tick species is well established. However, no clear evidence of their transmission by ticks is currently available. Detecting this pathogen in salivary glands is an important epidemiological result as it represents an additional indirect argument that this pathogen could be transmitted by tick bites. For each tick infected by A. phagocytophilum and R. helvetica, these bacteria were most often simultaneously detected in both midgut and salivary glands and only sometimes in either the midgut or salivary glands alone. These results are important in terms of pathogen transmission as they suggest that not all bacterial cells migrate together from the midgut to salivary glands, and that some infected females (with pathogens only in the midgut) would not necessarily be infectious. In contrast to $R$. helvetica, we only detected $R$. felis in the salivary glands of both males and females. Rickettsia felis is known to be mainly transmitted from cat to cat via fleas, with human contamination arising from cat or flea bites. Already detected in engorged Rhipicephalus sanguineus [33, 34], two studies have also identified this pathogen in questing I. ricinus nymphs ([35], Lejal et al., unpublished data). Detecting this pathogen only in salivary glands could suggest that it does not remain in the midgut and rapidly migrates to the salivary glands. This result also implies that $R$. felis would already be present in salivary glands at the time of the next blood-feeding and thus might be rapidly transmitted after the tick bite. While the presence and prevalence of this pathogenic agent are rarely investigated in studies dealing with tick-borne pathogens, this new detection in I. ricinus, and specifically in the salivary glands, should encourage us to increase our surveillance for this pathogen causing spotted fever in humans. Future investigations should be carried out to clarify the potential vector competence of I. ricinus for this pathogen and its role in transmission.

Borrelia miyamotoi of the Borrelia recurrent fever group and the parasite Babesia venatorum were only detected in males. That they were detected in general was not surprising as they have already been identified in many European countries [4, 6, 10, 36-43]. Interestingly, these pathogenic agents were found in both salivary glands and midgut, suggesting, particularly for B. miyamotoi, that migration from midgut to salivary glands is not triggered by a blood meal. Detecting these pathogens in salivary glands is particularly significant in terms of public and animal health. Indeed, in the event that females are infected with these pathogens $[6,44]$, it seems that both organs could be potential reservoirs for these pathogenic agents, thus potentially facilitating rapid transmission after a tick bite. It will of course be necessary to verify whether the $B$. venatorum parasites residing in salivary glands are actually infectious.

\section{Potential associations between pathogens}

We note finally that among all infected ticks, co-infections were observed in $20 \%$ of males and $24 \%$ of females. At a finer scale, between 10 and $21 \%$ of organs were coinfected. With detection tools becoming more sensitive and efficient, tick co-infections are observed with greater frequency $[6,8,12,13,39,45,46]$, suggesting that tick co-infection is the rule rather than the exception [6]. In this study, this hypothesis could also be extended to the level of individual tick organs. These observations, particularly co-infection in salivary glands, are particularly relevant to public health, as the tick disease community is starting to accept that pathogen co-transmission might significantly modify disease symptoms and severity [17, $18,47]$. The most common bacterial co-infection in male salivary glands and midgut was $R$. helvetica $+A$. phagocytophilum, whereas in females, the most frequent association in salivary glands and midgut was $R$. helvetica $+B$. lusitaniae. Our data contrast with previous findings performed in whole ticks demonstrating that the most common $I$. ricinus co-infection was $B$. garinii and $B$. afzelii $[6,8]$. Analysing TBP co-infections at a finer scale clearly enables us to highlight other potential associations not detected at the level of the whole tick. 


\section{Conclusions}

Analysing tick-borne pathogen composition and infection rates at the scale of individual tick organs highlighted (i) some pathogen location results which contrasted with well-established transmission mechanism postulates; (ii) novel findings in terms of pathogen location and migration time from midgut to salivary glands; and (iii) other potential associations between pathogens not detected at the scale of whole ticks. All findings should be confirmed using RNA extracts in order to verify if pathogens are indeed viable and actively replicating, to validate our hypotheses. This study represents another step towards generating improved control methods for tick-borne diseases and highlights the importance of investigating TBP infection at all scales (i.e. whole ticks $v s$ organs) to better understand the ecology and epidemiology of tick-borne diseases. To identify the microbiota influence on pathogens, it would be interesting to characterise the microbiota in both $I$. ricinus male and female salivary glands and midgut to detect potential co-occurrences between pathogens and other microbes.

\section{Methods}

\section{Tick collection and organ dissection}

A total of 30 female and 30 male questing I. ricinus ticks were collected in May 2017 by flagging in the Senart forest $\left(48^{\circ} 40^{\prime} \mathrm{N}, 2^{\circ} 29^{\prime} \mathrm{E}\right)$, south of Paris, France. Females and males were placed in separate sampling tubes. Before dissection, all ticks were washed once in $70 \%$ ethanol for $5 \mathrm{~min}$ and twice in distilled water for $5 \mathrm{~min}$ [48]. Tick organs, midgut and salivary glands, were then dissected in ice-cold PBS $(\mathrm{pH}=7.2)$. The 120 samples were then conserved at $-80^{\circ} \mathrm{C}$ until the DNA extraction.

\section{DNA extraction}

Tissue samples were individually crushed with glass beads using a Precellys ${ }^{\circledR} 24$ Dual homogeniser (Bertin technologies, Paris, France) at $5500 \times \mathrm{rpm}$ for $20 \mathrm{~s}$. Genomic DNA was then extracted using a Nucleospin tissue DNA extraction Kit (Macherey-Nagel, Hoerdt, France). For each sample, total DNA was eluted in $50 \mu \mathrm{l}$ of rehydration solution and stored at $-20^{\circ} \mathrm{C}$ until further analysis.

\section{High-throughput screening of bacterial and parasitic tick-borne pathogens}

A BioMark ${ }^{\mathrm{TM}}$ real-time PCR system (Fluidigm, USA) was used for high-throughput microfluidic real-time PCR for the most common bacterial and parasitic TBP species known to circulate or emerge in Europe. For bacteria, seven species belonging to the Lyme spirochete group Borrelia burgdorferi (s.l.) were tested: Borrelia burgdorferi (s.s.), Borrelia afzelii, Borrelia garinii, Borrelia spielmanii, Borrelia valaisiana, Borrelia lusitaniae and Borrelia bissettii. We also tested one species belonging to the Borrelia recurrent fever group, Borrelia miyamotoi; six species of Anaplasma (Anaplasma phagocytophilum, Anaplasma platys, Anaplasma marginale, Anaplasma ovis, Anaplasma centrale and Anaplasma bovis); six species of Rickettsia from the spotted fever group (Rickettsia felis, Rickettsia helvetica, Rickettsia conorii, Rickettsia slovaca, Rickettsia massiliae and Rickettsia aeschlimannii); Ehrlichia canis, "Candidatus Neoehrlichia mikurensis", Bartonella henselae, Francisella tularensis, Coxiella burnetii and Mycoplasma spp. For apicomplexan parasites, seven species of Babesia: Babesia canis, Babesia ovis, Babesia microti, Babesia bovis, Babesia caballi, Babesia venatorum and Babesia divergens, Theileria spp. and Hepatozoon spp. were tested. Extraction and amplification controls were included using DNA extracts from $I$. ricinus and $E$. coli respectively.

As previously described in Moutailler et al. [6], a DNA pre-amplification step was performed for each sample in a final volume of $5 \mu \mathrm{l}$ containing $2.5 \mu \mathrm{l}$ of TaqMan PreAmp Master Mix $(2 \times), 1.2 \mu \mathrm{l}$ of the pooled primer mix $(0.2 \times)$ and $1.3 \mu \mathrm{l}$ of tick DNA, with one cycle at $95{ }^{\circ} \mathrm{C}$ for $10 \mathrm{~min}, 14$ cycles at $95{ }^{\circ} \mathrm{C}$ for $15 \mathrm{~s}$, followed by $4 \mathrm{~min}$ at $60{ }^{\circ} \mathrm{C}$. Following pre-amplification, qPCRs were performed using FAM- and black hole quencher (BHQ1)-labelled TaqMan probes [48] with TaqMan Gene Expression Master Mix in accordance with manufacturer's instructions (Applied Biosystems, Illkirch, France). Thermal cycling conditions were as follows: $95{ }^{\circ} \mathrm{C}$ for 5 min, 45 cycles at $95^{\circ} \mathrm{C}$ for $10 \mathrm{~s}, 60^{\circ} \mathrm{C}$ for $15 \mathrm{~s}$ and $40{ }^{\circ} \mathrm{C}$ for $10 \mathrm{~s}$. Data were acquired on the BioMark ${ }^{\mathrm{TM}}$ Real-Time PCR system and analysed using the Fluidigm Real-Time PCR Analysis software to obtain crossing point (CP) values.

\section{Abbreviation \\ TBP: tick-borne pathogens.}

\section{Acknowledgements}

We thank the VECTOTIQ team members in the BIPAR unit for stimulating discussion and support.

\section{Funding}

The present study was funded by the Animal Health Department of the French National Institute for Agricultural Research (France).

\section{Availability of data and materials}

The datasets used and/or analysed during the present study are available from the corresponding author upon reasonable request.

Authors' contributions

Conceived and designed the experiments: TP and MVT. Performed the experiments: EJ, LS and TP. Analysed the data: EJ, TP and SM. Wrote the paper: EJ, SM, LS, MVT and TP. All authors read and approved the final manuscript. 
Ethics approval and consent to participate

Not applicable.

\section{Consent for publication}

Not applicable.

\section{Competing interests}

The authors declare that they have no competing interests.

\section{Publisher's Note}

Springer Nature remains neutral with regard to jurisdictional claims in published maps and institutional affiliations.

\section{Author details}

1 UMR BIPAR, Animal Health Laboratory, INRA, ANSES, Ecole Nationale Vétérinaire d'Alfort, Université Paris-Est, Maisons-Alfort, France. ${ }^{2}$ INRA, Animal Health Department, Nouzilly, France.

Received: 7 January 2019 Accepted: 27 March 2019

Published online: 02 April 2019

\section{References}

1. Reis C, Cote M, Paul REL, Bonnet S. Questing ticks in suburban forest are infected by at least six tick-borne pathogens. Vector Borne Zoonotic Dis. 2011;11:907-16.

2. Estrada-Peña A, Ortega C, Sanchez N, DeSimone L, Sudre B, Suk JE, et al. Correlation of Borrelia burgdorferi sensu lato prevalence in questing Ixodes ricinus ticks with specific abiotic traits in the western Palearctic. Appl Environ Microbiol. 2011;77:3838-45.

3. Coipan EC, Jahfari S, Fonville M, Maassen CB, Giessen JVD, Takken W, et al. Spatiotemporal dynamics of emerging pathogens in questing /xodes ricinus. Front Cell Infect Microbiol. 2013;3:36.

4. Reye AL, Stegniy V, Mishaeva NP, Velhin S, Hubschen JM, Ignatyev G, et al. Prevalence of tick-borne pathogens in Ixodes ricinus and Dermacentor reticulatus ticks from different geographical locations in Belarus. PLoS ONE 2013:8:e54476.

5. Jahfari S, Hofhuis A, Fonville M, van der Giessen J, van Pelt W, Sprong H. Molecular detection of tick-borne pathogens in humans with tick bites and erythema migrans, in the Netherlands. PLoS Negl Trop Dis. 2016:10:e0005042.

6. Moutailler S, Valiente Moro C, Vaumourin E, Michelet L, Tran FH, et al. Coinfection of ticks: the rule rather than the exception. PLoS Negl Trop Dis. 2016;10:e0004539.

7. Marchant A, Le Coupanec A, Joly C, Perthame E, Sertour N, Garnier M, et al. Infection of Ixodes ricinus by Borrelia burgdorferi sensu lato in periurban forests of France. PLoS One. 2017:12:e0183543.

8. Raileanu C, Moutailler S, Pavel I, Porea D, Mihalca AD, Savuta G, et al. Borrelia diversity and co-infection with other tick-borne pathogens in ticks. Front Cell Infect Microbiol. 2017:7:36.

9. Schotta AM, Wijnveld M, Stockinger H, Stanek G. Approaches for reverse line blot based detection of microbial pathogens in /xodes ricinus ticks collected in Austria and impact on chosen method. Appl Environ Microbiol. 2017:83:e00489-17.

10. Szekeres S, Lügner J, Fingerle V, Margos G, Földvari G. Prevalence of Borrelia miyamotoi and Borrelia burgdorferi sensu lato in questing ticks from a recreational coniferous forest of East Saxony, Germany. Ticks Tick Borne Dis. 2017;8:922-7.

11. Chvostac M, Spitalska E, Vaclav R, Vaculova T, Minichova L, Derdakova M Seasonal patterns in the prevalence and diversity of tick-borne Borrelia burgdorferi sensu lato, Anaplasma phagocytophilum and Rickettsia spp. in an urban temperate forest in south-western Slovakia. Int J Environ Res Public Health. 2018;15:994.

12. Halos L, Jamal T, Maillard R, Beugnet F, Le Menach A, Boulouis HJ, et al. Evidence of Bartonella sp. in questing adult and nymphal Ixodes ricinus ticks from France and co-infection with Borrelia burgdorferi sensu lato and Babesia sp. Vet Res. 2005:36:79-87.
13. Andersson M, Bartkova S, Lindestad O, Raberg L. Co-infection with 'Candidatus Neoehrlichia mikurensis' and Borrelia afzelii in Ixodes ricinus ticks in southern Sweden. Vector Borne Zoonotic Dis. 2013;13:438-42.

14. Berggoetz M, Schmid M, Ston D, Wyss V, Chevillon C, Pretorius AM, et al. Protozoan and bacterial pathogens in tick salivary glands in wild and domestic animal environments in South Africa. Ticks Tick Borne Dis. 2014:5:176-85.

15. Grunwaldt E, Barbour AG, Benach JL. Simultaneous occurrence of babesiosis and Lyme disease. N Engl J Med. 1983:308:1166.

16. Golightly LM, Hirschhorn LR, Weller PF. Fever and headache in a splenectomized woman. Rev Infect Dis. 1989;11:629-37.

17. Swanson SJ, Neitzel D, Reed KD, Belongia EA. Co-infections acquired from Ixodes ticks. Clin Microbiol Rev. 2006:19:708-27.

18. Diuk-Wasser MA, Vannier E, Krause PJ. Coinfection by Ixodes tick-borne pathogens: ecological, epidemiological, and clinical consequences. Trends Parasitol. 2016:32:30-42.

19. Santos AS, Bacellar F, Santos-Silva M, Formosinho P, Gracio AJ, Franca S. Ultrastructural study of the infection process of Rickettsia conorii in the salivary glands of the vector tick Rhipicephalus sanguineus. Vector Borne Zoonotic Dis. 2002:2:165-77.

20. Futse JE, Ueti MW, Knowles DP, Palmer GH. Transmission of Anaplasma marginale by Boophilus microplus: retention of vector competence in the absence of vector-pathogen interaction. J Clin Microbiol. 2003:41:3829-34

21. Popov VL, Korenberg El, Nefedova WV, Han VC, Wen JW, Kovaleskii YV, et al. Ultrastructural evidence of the ehrlichial developmental cycle in naturally infected Ixodes persulcatus ticks in the course of coinfection with Rickettsia, Borrelia, and a flavivirus. Vector Borne Zoonotic Dis. 2007;7:699-716.

22. Narasimhan S, Rajeevan N, Liu L, Zhao YO, Heisig J, Pan J, et al. Gut microbiota of the tick /xodes scapularis modulate colonization of the Lyme disease spirochetes. Cell Host Microbe. 2014;15:58-71.

23. Piesman J, Schneider BS. Dynamic changes in Lyme disease spirochetes during transmission by nymphal ticks. Exp Appl Acarol. 2002;28:141-5.

24. Ueti MW, Reagan JO, Knowles DP, Scoles GA, Shkap V, Palmer GH. Identification of midgut and salivary glands as specific and distinct barriers to efficient tick-borne transmission of Anaplasma marginale. Infect Immun. 2007;75:2959-64.

25. Hajdusek O, Sima R, Ayllon N, Jalovecka M, Perner J, de la Fuente J, et al. Interaction of the tick immune system with transmitted pathogens. Front Cell Infect Microbiol. 2013;3:26.

26. Halos L, Bord S, Cotte V, Gasqui P, Abrial D, Barnouin J, et al. Ecological factors characterizing the prevalence of bacterial tick-borne pathogens in Ixodes ricinus ticks in pastures and woodlands. Appl Environ Microbiol. 2010;76:4413-20.

27. Des Vignes F, Piesman J, Heffernan R, Schulze TL, Stafford KC, Fish D. Effect of tick removal on transmission of Borrelia burgdorferi and Ehrlichia phagocytophila by Ixodes scapularis nymphs. J Infect Dis. 2001;183:773-8.

28. Piesman J, Schneider BS, Zeidner NS. Use of quantitative PCR to measure density of Borrelia burgdorferi in the midgut and salivary glands of feeding tick vectors. J Clin Microbiol. 2001;39:4145-8.

29. Kung F, Anguita J, Pal U. Borrelia burgdorferi and tick proteins supporting pathogen persistence in the vector. Future Microbiol. 2013;8:41-56.

30. Sertour N, Cotté V Garnier M, Malandrin L, Ferquel E, Choumet V. Infection kinetics and tropism of Borrelia burgdorferi sensu lato in mouse after natural (via ticks) or artificial (needle) infection depends on the bacterial strain. Front Microbiol. 2018;9:1722.

31. Pospisilova T, Urbanova V, Hes O, Kopacek P, Hajdusek O, Sima R. Tracking Borrelia afzelii from Ixodes ricinus nymphs to mice suggests a direct gut to mouth route of Lyme disease transmission. BioRxiv. 2018;67:78. https:// doi.org/10.1101/316927.

32. Alberdi MP, Walker AR, Paxton EA, Sumption KJ. Natural prevalence of infection with Ehrlichia phagocytophila of Ixodes ricinus ticks in Scotland. Vet Parasitol. 1998;78:203-13.

33. Oliveira KA, Oliveira LS, Dias CC, Silva A, Almeida MR, Almeda G, et al, Molecular identification of Rickettsia felis in ticks and fleas from an endemic area for Brazilian spotted fever. Mem Inst Oswaldo Cruz. 2008;103:191-4.

34. Abarca K, Lopez J, Acosta-Jamett G, Martinez-Valdebenito C. Rickettsia felis in Rhipicephalus sanguineus from two distant Chilean cities. Vector Borne Zoonotic Dis. 2013;13:607-9. 
35. Vayssier-Taussat M, Moutailler S, Michelet L, Devillers E, Bonnet S, Cheval $J$, et al. Next generation sequencing uncovers unexpected bacterial pathogens in ticks in western Europe. PLoS One. 2013;8:e81439.

36. Fraenkel CJ, Garpmo U, Berglund J. Determination of novel Borrelia genospecies in Swedish Ixodes ricinus ticks. J Clin Microbiol. 2002;40:3308-12.

37. Richter D, Schlee DB, Matuschka FR. Relapsing fever like spirochetes infecting European vector tick of Lyme disease agent. Emerg Infect Dis. 2003;9:697-701.

38. Geller J, Nazarova L, Katargina O, Jarvekulg L, Fomenko N, Golovljova I. Detection and genetic characterization of relapsing fever spirochete Borrelia miyamotoi in Estonian ticks. PLoS One. 2012;7:e51914.

39. Cosson JF, Michelet L, Chotte J, Le Naour E, Cote M, Devillers E, et al. Genetic characterization of the human relapsing fever spirochete Borrelia miyamotoi in vectors and animal reservoirs of Lyme disease spirochetes in France. Parasit Vectors. 2014;7:233.

40. Sakakibara K, Sen E, Sato K, Kawabata H, Ohashi N, Masuzawa T. Detection and characterization of the emerging relapsing fever pathogen, Borrelia miyamotoi, from the Ixodes ricinus tick in the rural Trakya region of northwestern Turkey. Vector Borne Zoonotic Dis. 2016;16:797-9.

41. Paul REL, Cote M, Le Naour E, Bonnet S. Environmental factors influencing tick densities over seven years in a French suburban forest. Parasit Vectors. 2016;9:309.
42. Oechslin CP Heutschi D, Lenz N, Tischhauser W Peter O, Rais O, et al. Prevalence of tick-borne pathogens in questing Ixodes ricinus ticks in urban and suburban areas of Switzerland. Parasit Vectors. 2017:10:558

43. Wagemaker A, Jahfari S, de Wever B, Spanjaard L, Starink MV, de Vries HJC, et al. Borrelia miyamotoi in vectors and hosts in the Netherlands. Ticks Tick Borne Dis. 2017;8:370-4.

44. Diaz P, Arnal JL, Remesar S, Perez-Creo A, Venzal JM, Vasquez-Lopez ME, et al. Molecular identification of Borrelia spirochetes in questing Ixodes ricinus from north-western Spain. Parasit Vectors. 2017:10:615.

45. Schicht S, Junge S, Schnieder T, Strube C. Prevalence of Anaplasma phagocytophilum and coinfection with Borrelia burgdorferi sensu lato in the hard tick Ixodes ricinus in the city of Hanover (Germany). Vector Borne Zoonotic Dis. 2011;11:1595-7.

46. Castro LR, Gabrielli S, Iori A, Cancrini G. Molecular detection of Rickettsia, Borrelia, and Babesia species in Ixodes ricinus sampled in northeastern, central, and insular areas of Italy. Exp Appl Acarol. 2015;66:443-52.

47. Krause PJ, Telford SR 3rd, Spielman A, Sikand V, Ryan R, Christianson D, et al. Concurrent Lyme disease and babesiosis. Evidence for increased severity and duration of illness. JAMA. 1996;275:1657-60.

48. Michelet L, Delannoy S, Devillers E, Umhang G, Aspan A, Juremalm M et al. High-throughput screening of tick-borne pathogens in Europe. Front Cell Infect Microbiol. 2014:4:103.
Ready to submit your research? Choose BMC and benefit from:

- fast, convenient online submission

- thorough peer review by experienced researchers in your field

- rapid publication on acceptance

- support for research data, including large and complex data types

- gold Open Access which fosters wider collaboration and increased citations

- maximum visibility for your research: over $100 \mathrm{M}$ website views per year

At BMC, research is always in progress.

Learn more biomedcentral.com/submissions 